\title{
Ten-year survival and recurrence of hepatocellular cancer
}

\author{
Tomoki Sempokuya ${ }^{1,2}$, Linda L. Wong ${ }^{3}$ \\ 'Department of Medicine, John A. Burns School of Medicine, University of Hawaii at Manoa, Honolulu, Hawaii, HI 96813, USA. \\ 2Division of Gastroenterology and Hepatology, University of Nebraska Medical Center, Omaha, Nebraska, NE 68198, USA. \\ ${ }^{3}$ Department of Surgery, John A. Burns School of Medicine, University of Hawaii at Manoa, Honolulu, Hawaii, HI 96813, USA.
}

Correspondence to: Linda L. Wong, Department of Surgery, John A. Burns School of Medicine, University of Hawaii at Manoa, Honolulu, Hawaii 550 South Beretania St., Suite 403, Honolulu, Hawaii, HI 96813, USA. E-mail: hepatoma@aol.com

How to cite this article: Sempokuya T, Wong LL. Ten-year survival and recurrence of hepatocellular cancer. Hepatoma Res 2019;5:38. http://dx.doi.org/10.20517/2394-5079.2019.013

Received: 9 Sep 2019 First Decision: 29 Sep 2019 Revised: 7 Oct 2019 Accepted: 8 Oct 2019 Published: 13 Oct 2019

Science Editor: Dalbir Sandhu Copy Editor: Rong-Rong Dou Production Editor: Jing Yu

\begin{abstract}
Aim: Long-term survival after hepatocellular cancer (HCC) is difficult to achieve likely related to recurrence. This study aimed to identify factors that were predictive of 10 -year survival after the diagnosis of HCC.

Methods: In a prospectively collected database of 1374 HCC cases (1993-2019), we identified 70 patients who survived over 10 years regardless of treatment. We then identified 164 patients in the entire cohort who either had liver resection or transplant, and died before 10 years. Demographics, tumor characteristics, treatment, recurrence and treatment of recurrence were compared.

Results: Of the 10-year survivors, 36 underwent transplant, 27 had liver resection and 7 patients had only locoregional therapy. Compared to the non-survivors, the 10-year survivors were younger and had fewer comorbidities or recurrence, smaller tumor size, lower AST, ALT, AFP, platelets, neutrophil-to-lymphocyte ratio. Multivariate analysis showed only age and diabetes to be negative predictors. Recurrence occurred in 24 survivors (34.3\%) with mean time to recurrence with standard deviation $57.1 \pm 42.6$ months compared to 80 non-survivors (48.7\%) with mean time to recurrence of $15.3 \pm 14.8$ months. For hepatic resection, 10 -year survivors had longer time to recurrence compared to non-survivors (median: 31.3 months).
\end{abstract}

Conclusion: Long-term survivors mostly occur after resection or transplant, but 10\% of our cohort survived 10 years with only locoregional therapy. Underlying health status maybe an important predictor of 10 -year survival for

\footnotetext{
(@) (

(C) The Author(s) 2019. Open Access This article is licensed under a Creative Commons Attribution 4.0 International License (https://creativecommons.org/licenses/by/4.0/), which permits unrestricted use, sharing, adaptation, distribution and reproduction in any medium or format, for any purpose, even commercially, as long as you give appropriate credit to the original author(s) and the source, provide a link to the Creative Commons license, and indicate if changes were made.
}

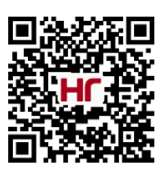


patients receiving liver resections. Recurrence of HCC occurs in both 10 -year survivors and non-survivors, but later recurrence with aggressive treatment of the recurrence may allow for 10-year survival.

Keywords: Hepatocellular cancer, 10-year survival, liver transplantation, hepatic resection

\section{INTRODUCTION}

Hepatocellular cancer (HCC) is the fourth leading cause of cancer mortality in the world and the incidence and mortality has been increasing in the USA ${ }^{[1,2]}$. Survival for HCC has been prolonged by curative therapies which include liver transplantation, hepatic resection and ablation ${ }^{[3]}$. The overall 5 -year survival for patients with HCC is quite dismal and estimated at 10\%-12\%, however this is improved in patients with localized HCC (30\%) and those who undergo liver transplantation $(70 \%-75 \%)^{[4,5]}$. Efforts have been made to promote early detection of HCC with surveillance programs as this can contribute to improved survival by allowing patients to qualify for these curative therapies ${ }^{[6]}$.

Despite these efforts and potentially curative therapies, recurrence occurs in about $54 \%$ of patients who undergo resection and $8 \%-17 \%$ of those who undergo liver transplantation ${ }^{[7-10]}$. Recurrences have been treated with repeat liver resections, salvage liver transplantation after resection and locoregional therapies, however these recurrences are likely responsible for compromised long-term survival. While much of the literature focuses on 5-year outcome, less is reported about longer term survival beyond 5 years. Late recurrence, which occurs after 5 years, has been described in patients after resection or transplant ${ }^{[1-13]}$. Others have suggested that underlying liver function as measured by albumin-bilirubin (ALBI) grade correlated with recurrence free survival $^{[14,15]}$.

There are few studies that report or critically evaluate 10-year survival from HCC. This is often difficult as patients relocate, have other illnesses, are lost to follow-up or are no longer followed by the tertiary center that performed the curative therapy. This study reviews a 26-year experience of patients in Hawaii with HCC who have been followed by a group of physicians and the state's only Liver Center and characterizes patients with at least 10-year follow-up from curative therapies. Specifically, we identified 10-year survivors and compared them to patients who received similar therapies who died before 10 years.

\section{METHODS}

\section{Patients}

Utilizing prospectively collected database of 1374 HCC patients from 1993 to 2019, there were 575 patients who had at least 10 years of follow up. We identified those patients who survived at least 10 years regardless of treatment. We then selected a comparison group of all patients who underwent liver transplantation or liver resection and did not survive 10 years. We excluded patients who had liver transplantation or resection who were still alive but did not have at least 10 years of follow up. This comparison group also excluded patients who had non-surgical therapies and did not survive 10 years as this was a large heterogeneous group of patients with more advanced HCC and/or severe cirrhosis who received locoregional therapy or supportive care. This database is based on Hawaii's only tertiary liver center and liver transplant program and also includes patients from the American territories of the Pacific Basin. Approximately $60 \%-70 \%$ of the HCC patients in Hawaii were referred to this center and included in this database. The diagnosis of HCC was made histologically or based on contrast-enhanced computed tomography scan or magnetic resonance imaging with typical HCC features based on guidelines published by the american association for the study of liver disease ${ }^{[3]}$. This study was approved by the university of hawaii at manoa institutional review board. 


\section{Data collected}

We obtained demographic (age, sex and ethnicity), anthropometric information [height, weight and body mass index (BMI)], comorbidities, etiology of HCC, tumor size/characteristics, laboratory values, staging, therapeutic modalities, recurrence and survival information. Ethnicity was categorized as "Caucasian", "Asian", "Pacific Islanders", and "Others". Comorbidity data collected include diabetes mellitus, smoking status, hyperlipidemia, and hypertension.

Significant alcohol use was defined as at least 2 alcoholic beverages daily for 10 years. Positive smoking history included both past and present use of cigarettes. Laboratory values include creatinine, alanine aminotransferase (ALT), aspartate aminotransferase (AST), albumin, bilirubin, prothrombin time with international normalized ratio, platelet, neutrophil, lymphocytes, hepatitis B virus (HBV) and hepatitis $\mathrm{C}$ virus (HCV) serologies and pre-treatment alpha feto protein (AFP). We defined normal AFP as less than $20 \mathrm{ng} / \mathrm{dL}$. Based on these values, we calculated model for End-Stage Liver Disease (MELD) score ${ }^{[16]}$, fibrosis-4 (FIB-4) index for liver fibrosis ${ }^{[17]}$, AST/platelet ratio index (APRI) and neutrophil-lymphocyte ratio (NLR). The American Joint Committee on Cancer (AJCC) staging system was incorporated with tumor size, number, and location of tumor. Tumor size was categorized by the largest diameter by $\geq 5 \mathrm{~cm}$ or $<5 \mathrm{~cm}$. Status on underlying cirrhosis, rupture at presentation, and macrovascular invasion on imaging was also noted. Cirrhosis was determined with imaging when tissue was not available. Therapeutic modalities included liver transplantation, hepatic resection and locoregional therapies (radiofrequency ablation (RFA), cryosurgery, transarterial chemoembolization (TACE), percutaneous ethanol injection and yttrium 90 transarterial radioembolization). Liver resection was performed on patients with ChildsTurcotte-Pugh (CTP) A and early B with CTP of 7 without ascites or encephalopathy. Patients who received liver transplantations had unresectable tumor who met Milan criteria ${ }^{[18]}$ or prior liver resection with recurrence of HCC which met Milan criteria. Single tumors size less than $6.5 \mathrm{~cm}$ that were down staged to meet Milan criteria was also evaluated for liver transplantation since 2007.

\section{Statistical analysis}

Statistical analysis was conducted using statistical package for social services (SPSS) (version 23.0. IBM Corp., Armonk, NY, USA), R version 3.4.1 (The R foundation for Statistical Computing, Vienna, Austria) as well as EZR version 1.36 (Division of Hematology, Saitama Medical Center, Jichi Medical University, $\left.\operatorname{Japan}^{[19]}\right)$. Primary objective of this study is to elucidate the factors associated with 10-year survival. Secondary objective of this study is to elucidate management strategies for HCC recurrence that allows for long term survival. Comparison of binary variables were accomplished by chi-square test. Continuous variables were analyzed by $\mathrm{T}$ test to obtain mean, standard deviation (SD) and standard error of mean (SE). Likelihood ratio was calculated for binary variables. Nominal regression was used to create a regression model. Variables included in this model as followings: age was categorized as a binary variable with $<65$-year-old and $\geq 65$-year-old. Demographic data, etiology of HCC, BMI, comorbidity, AFP as binary variable (normal vs abnormal), tumor size as a binary variable, Milan criteria, rupture status, and therapeutic modalities. Multivariable regression model was also created to analyze these variables with $P<0.1$ on univariate analysis. We also conducted differences between 10-year survivors and non-survivors on time to recurrence for transplant and hepatic resection. Kolmogorov-Smirnov test was used to test for normal distribution. Mann-Whitney $U$ test was used to compare time to recurrence and recurrence free survival between 10 -year survivors and non-survivors. $P<0.05$ is considered as statistically significant.

\section{RESULTS}

\section{Baseline characteristics}

This study included 234 patients: 70 patients who survived 10 years after the diagnosis of HCC and 164 patients in the entire cohort who either had liver resection or transplant and died before 10 years. Baseline 
Table 1. Baseline characteristics for all patients

\begin{tabular}{|c|c|c|c|c|c|}
\hline & $\begin{array}{l}\text { Locoregional therapy } \\
\qquad(n=7)\end{array}$ & $\begin{array}{l}\text { Resection } \\
(n=163)\end{array}$ & $\begin{array}{l}\text { Liver transplant } \\
\quad(n=64)\end{array}$ & $P$ value & Total $(n=234)$ \\
\hline Age $\geq 65$ years $(\%)$ & $2(28.5)$ & $75(46.0)$ & $4(6.3)$ & $<0.001$ & $153(65.4)$ \\
\hline Sex (Males) (\%) & $5(71.4)$ & $115(70.6)$ & $55(85.9)$ & 0.05 & $175(74.8)$ \\
\hline $\mathrm{BMI} \geq 25(\%)$ & $5(71.4)$ & $73(44.8)$ & $48(75.0)$ & 0.002 & $126(53.8)$ \\
\hline Diabetes (\%) & $1(14.3)$ & $47(28.9)$ & $18(28.1)$ & 0.70 & $66(28.2)$ \\
\hline Hepatitis B (\%) & $1(14.3)$ & $68(41.7)$ & $21(32.8)$ & 0.48 & $64(27.4)$ \\
\hline Hepatitis C (\%) & $5(71.4)$ & $43(26.4)$ & $38(59.4)$ & $<0.001$ & $86(36.8)$ \\
\hline Hyperlipidemia (\%) & $1(14.3)$ & $41(25.2)$ & $7(10.9)$ & 0.04 & $49(20.9)$ \\
\hline Hypertension (\%) & $5(71.4)$ & $88(54.0)$ & $28(43.8)$ & 0.12 & $121(51.7)$ \\
\hline AJCC Stages & & & & 0.08 & \\
\hline Stage I & $7(100)$ & 109 (66.9) & $49(76.6)$ & & $165(70.5)$ \\
\hline Stage II & $0(0)$ & $17(10.4)$ & $13(20.3)$ & & $30(12.8)$ \\
\hline Stage IIla & $0(0)$ & $1(0.6)$ & $0(0)$ & & $1(0.4)$ \\
\hline Stage IIIb & $0(0)$ & $11(6.7)$ & $0(0)$ & & $11(4.7)$ \\
\hline Stage IIIc & $0(0)$ & $5(3.0)$ & $2(3.1)$ & & $7(3.0)$ \\
\hline Stage III NOS & $0(0)$ & $1(0.6)$ & $0(0)$ & & $1(0.4)$ \\
\hline Stage IV & $0(0)$ & $18(11.0)$ & $0(0)$ & & $18(7.7)$ \\
\hline Single tumor & $7(100)$ & $131(80.4)$ & $51(79.7)$ & 0.42 & $189(80.8)$ \\
\hline Cirrhosis & $7(100)$ & $68(41.7)$ & $63(98.4)$ & $<0.001$ & $138(60.0)$ \\
\hline Normal AFP (\%) & $3(42.9)$ & $74(45.4)$ & $29(45.3)$ & 0.99 & $106(45.3)$ \\
\hline Rupture (\%) & $0(0)$ & $18(11.0)$ & $0(0)$ & 0.01 & $18(7.7)$ \\
\hline Size $\geq 5$ cm (\%) & $3(42.9)$ & $98(60.1)$ & $6(9.4)$ & $<0.001$ & $107(45.7)$ \\
\hline Vascular invasion (\%) & $0(0)$ & $6(3.7)$ & $2(3.1)$ & 0.86 & $8(3.4)$ \\
\hline
\end{tabular}

BMI: body mass index; AJCC: American Joint Committee on Cancer; NOS: not otherwise specified; AFP: alpha feto protein

characteristics are shown in Table 1. In the entire cohort, mean age was 60.2 years (SD: 10.6) with 153 patients (65.4\%) older than 65-year, 175 (74.8\%) were male, and $126(53.8 \%)$ had BMI over 25. Ethnic distribution was as follows: 160 (68.4\%) were Asian, 42 (17.9\%) were Caucasian, 24 (10.3\%) were Pacific Islanders, and $8(3.4 \%)$ were mixed or another ethnicity. The incidence of risk factors included: $36.8 \%$ had prior HCV, $27.4 \%$ had prior HBV, $34.6 \%$ has alcohol usage, and $12.8 \%$ had NASH/NAFLD. For comorbid conditions, $125(53.4 \%)$ had a smoking history, 66 (28.2\%) had diabetes, 49 (20.9\%) had hyperlipidemia, and 121 (51.7\%) had hypertension. For tumor characteristics, 107 (45.7\%) had tumor size $\geq 5 \mathrm{~cm}, 106$ (45.3\%) had normal AFP, and 108 (46.2\%) met Milan criteria for liver transplantation. For treatment, 64 (27.4\%) received liver transplantation, 163 (69.7\%) had resection, and 7 patients had only locoregional therapy. For each treatment modalities, age, $\mathrm{BMI} \geq 25, \mathrm{HCV}$, hyperlipidemia, tumor rupture, and size $\geq 5 \mathrm{~cm}$ had statistically significant difference among curative therapies. Of note, six patients had salvage transplant. More than half of the patients who were transplanted received locoregional therapy prior to transplant.

\section{0-year survivors vs, non-survivors}

Tables 2 and 3 summarize the characteristics of 10-year survivors vs. non-survivors. There was no difference in ethnic distribution between the groups. As shown in Tables 2 and 3, 10-year survivors were younger and had a smaller tumor size and lower AFP, AST, ALT, platelets and NLR compared to non 10-year survivors. Univariate analysis showed that 10-year survivors were less likely to be age $\geq 65$ years or to have diabetes, hypertension or tumors $\geq 5 \mathrm{~cm}$ [Table 4]. Multivariate analysis showed only age and diabetes to be predictive of survival. Of the 10-year survivors, 36 underwent transplant, 27 had liver resection and 7 patients had only locoregional therapy. We performed separate analysis for transplantation and hepatic resection to compare 10-year survivors and non-survivors. Details are shown in Tables 5 and 6 . For liver transplantation, HCC found with surveillance, hypertension and recurrence were significantly different in the univariate analysis. However, in the multivariate analysis, only the presence of recurrence was predictive of not surviving 10 years. For liver resection, Age $\geq 65$-year, Hepatitis B, BMI $\geq 25$, diabetes, hypertension, and smoking status had significant difference between two groups on the univariate analysis. Only BMI $\geq 25$ and smoking were predictive of not surviving 10 years in the multivariate analysis. 
Table 2. Patient characteristics of 10 -year survivors vs. non-survivors

\begin{tabular}{|c|c|c|c|}
\hline & 10-year survivors $(n=70)$ & 10-year Non-survivors $(n=164)$ & $P$ value \\
\hline Age in years & $55.5 \pm 7.5$ & $62.2 \pm 11.0$ & $<0.001$ \\
\hline Age $\geq 65$ years $(\%)$ & $12(17.1)$ & $69(42.1)$ & $<0.001$ \\
\hline Sex (Males) & $57(81.4)$ & $118(72.0)$ & 0.17 \\
\hline $\mathrm{BMI} \geq 30(\%)$ & $12(17.1)$ & $31(18.9)$ & 0.77 \\
\hline Diabetes (\%) & $9(12.9)$ & $57(34.8)$ & 0.001 \\
\hline Hypertension (\%) & $31(44.3)$ & $90(54.9)$ & 0.001 \\
\hline Hyperlipidemia (\%) & $11(15.7)$ & $38(23.2)$ & 0.24 \\
\hline Smoking (\%) & $35(50.0)$ & $90(54.9)$ & 0.56 \\
\hline Alcohol use (\%) & $27(38.6)$ & $54(32.9)$ & 0.50 \\
\hline Hepatitis B (\%) & $30(42.9)$ & $60(36.6)$ & 0.12 \\
\hline Hepatitis C (\%) & $28(40.0)$ & $58(35.4)$ & 0.62 \\
\hline AJCC stages & & & 0.09 \\
\hline Stage I & $56(80.0)$ & $109(66.4)$ & \\
\hline Stage II & $11(15.7)$ & $19(11.6)$ & \\
\hline Stage Illa & $1(1.4)$ & $10(6.3)$ & \\
\hline Stage IIIb & $0(0)$ & $7(4.3)$ & \\
\hline Stage IIIc & $0(0)$ & $1(0.6)$ & \\
\hline Stage III NOS & $0(0)$ & $1(0.6)$ & \\
\hline Stage IV & $2(2.9)$ & $16(9.8)$ & \\
\hline Single tumor & $58(82.9)$ & $131(79.9)$ & 0.73 \\
\hline Cirrhosis & $51(72.9)$ & $87(53.0)$ & 0.01 \\
\hline HCC found with surveillance (\%) & $12(17.1)$ & $27(16.5)$ & 1.00 \\
\hline $\mathrm{AST}(I U / L)$ & $64.3 \pm 45.5$ & $73.6 \pm 58.9$ & 0.03 \\
\hline $\operatorname{ALT}(I U / L)$ & $60.5 \pm 38.5$ & $64.0 \pm 52.4$ & 0.03 \\
\hline Platelets $\left(\times 10^{3} / \mathrm{cc}\right)$ & $149.6 \pm 77.3$ & $190.5 \pm 101.2$ & 0.03 \\
\hline FIB-4 & $4.32 \pm 3.16$ & $4.11 \pm 3.66$ & 0.07 \\
\hline APRI & $0.62 \pm 0.63$ & $0.57 \pm 0.75$ & 0.94 \\
\hline Creatinine $(\mathrm{mg} / \mathrm{dL})$ & $0.88 \pm 0.21$ & $1.01 \pm 0.59$ & 0.03 \\
\hline Neutrophil/Lymphocyte ratio & $2.33 \pm 1.88$ & $4.20 \pm 3.50$ & 0.002 \\
\hline MELD & $9.10 \pm 3.3$ & $9.28 \pm 3.2$ & 0.62 \\
\hline $\operatorname{AFP}(\mathrm{mg} / \mathrm{dL})$ & $2479 \pm 14,355$ & $13787 \pm 81,011$ & 0.049 \\
\hline
\end{tabular}

Numerical values expressed as \pm standard deviation. BMI: body mass index; AJCC: The American Joint Committee on Cancer staging system; NOS: not otherwise specified; HCC: hepatocellular cancer; AST: aspartate aminotransferase; ALT: alanine aminotransferase; FIB4: fibrosis-4 Index; APRI: AST/Platelet Ratio Index; MELD: Model for End-stage Liver Disease Score; AFP: alpha feto protein

Table 3. Tumor characteristics and treatment of 10-year survivors vs, non-survivors

\begin{tabular}{lccc}
\hline & 10-year survivors $(\boldsymbol{n}=\mathbf{7 0})$ & 10-year Non-survivors $(\boldsymbol{n}=\mathbf{1 6 4})$ & $\boldsymbol{P}$ value \\
\hline Mean tumor size (cm \pm SD) & $4.0 \pm 2.4$ & $6.7 \pm 4.7$ & $<0.001$ \\
Tumor size $\geq 5 \mathrm{~cm}(\%)$ & $23(35.4)$ & $84(51.2)$ & 0.01 \\
Single tumor (\%) & $58(82.9)$ & $131(79.9)$ & 0.73 \\
Rupture (\%) & $2(2.9)$ & $16(9.8)$ & 0.12 \\
Vascular invasion (\%) & $0(0)$ & $8(4.9)$ & 0.14 \\
Met Milan Criteria (\%) & $40(57.1)$ & $68(41.5)$ & 0.04 \\
Treatment & & & $<0.001^{\star}$ \\
Transplantation (\%) & $36(51.4)$ & $28(17.1)$ & \\
Resection (\%) & $27(38.6)$ & $136(82.9)$ & \\
Locoregional therapy (\%) & $7(10.0)$ & $0(0)$ & 0.04 \\
Recurrence (\%) & $24(34.3)$ & $80(48.8)$ & \\
\hline
\end{tabular}

${ }^{\star}$ There was also significant difference between transplantation and resection $(P<0.001)$. SD: standard deviation

\section{Recurrence}

Of the 10-year survivors, recurrence occurred in 24 patients (34.3\%) with mean time to recurrence with $\mathrm{SD}, 57.1 \pm 42.6$ months days and 23 of these patients had treatment for their recurrence. In 164 non 10 -year survivors, 136 had liver resection and 28 had liver transplant. Recurrence occurred in 80 patients 
Table 4. Predictors of 10-year survival (all patients)

\begin{tabular}{|c|c|c|}
\hline & Univariate odds-ratio $(95 \% \mathrm{Cl})$ & Multivariate odds-ratio $(95 \% \mathrm{Cl})$ \\
\hline Age $\geq 65$ & $0.29(0.14-0.57)$ & $0.33(0.15-0.72)$ \\
\hline Sex (Males) & $1.71(0.86-3.41)$ & \\
\hline Hepatitis B & $1.30(0.74-2.30)$ & \\
\hline Hepatitis C & $1.21(0.68-2.15)$ & \\
\hline Alcohol history & $1.28(0.72-2.29)$ & \\
\hline NASH/NAFLD & $0.43(0.16-1.17)$ & $1.07(0.32-3.52)$ \\
\hline HCC found with surveillance & $1.05(0.50-2.21)$ & \\
\hline $\mathrm{BMI} \geq 25$ & $0.84(0.48-1.50)$ & \\
\hline $\mathrm{BMI} \geq 30$ & $0.84(0.40-1.75)$ & \\
\hline Smoking & $0.81(0.46-1.42)$ & \\
\hline Diabetes mellitus & $0.28(0.13-0.60)$ & $0.28(0.12-0.68)$ \\
\hline Hyperlipidemia & $0.60(0.29-1.27)$ & \\
\hline Hypertension & $0.36(0.20-0.66)$ & $0.66(0.33-1.31)$ \\
\hline Normal AFP & $0.67(0.38-1.18)$ & \\
\hline Size $\geq 5 \mathrm{~cm}$ & $0.47(0.26-0.84)$ & $0.52(0.14-1.91)$ \\
\hline Met Milan criteria & $1.86(1.06-3.28)$ & $0.69(0.20-2.41)$ \\
\hline Rupture & $0.27(0.06-1.22)$ & $0.36(0.07-1.85)$ \\
\hline
\end{tabular}

Significant values are in bold. NASH: non-alcoholic steatohepatitis; NAFLD: Non-alcoholic fatty liver disease; HCC: hepatocellular cancer; BMI: body mass index; AFP: alpha feto protein

Table 5. Predictors of 10-year survival after transplant

\begin{tabular}{|c|c|c|}
\hline & Univariate odds-ratio $(95 \% \mathrm{Cl})$ & Multivariate odds-ratio $(95 \% \mathrm{Cl})$ \\
\hline Age $\geq 65$ & $2.45(0.24-25.0)$ & \\
\hline Sex (Males) & $3.0(0.66-13.3)$ & \\
\hline Hepatitis B & $1.41(0.49-4.10)$ & \\
\hline Hepatitis C & $0.53(0.19-1.48)$ & \\
\hline Alcohol history & $0.92(0.34-2.49)$ & \\
\hline NASH/NAFLD & $0.76(0.14-4.08)$ & \\
\hline HCC found with surveillance & $0.29(0.09-0.98)$ & $0.29(0.07-1.21)$ \\
\hline $\mathrm{BMI} \geq 25$ & $0.71(0.22-2.26)$ & \\
\hline $\mathrm{BMI} \geq 30$ & $0.86(0.27-2.74)$ & \\
\hline Smoking & $1.40(0.52-3.78)$ & \\
\hline Diabetes & $0.37(0.12-1.14)$ & $0.51(0.12-2.20)$ \\
\hline Hyperlipidemia & $1.04(0.21-5.09)$ & \\
\hline Hypertension & $0.32(0.10-0.98)$ & $0.28(0.06-1.34)$ \\
\hline Normal AFP & $0.55(0.20-1.50)$ & \\
\hline Size $\geq 5 \mathrm{~cm}$ & $1.62(0.28-9.58)$ & \\
\hline Single tumor & $1.13(0.33-3.84)$ & \\
\hline Recurrence & $0.29(0.09-0.98)$ & $0.19(0.03-1.02)$ \\
\hline
\end{tabular}

Significant values are in bold. NASH: non-alcoholic steatohepatitis; NAFLD: non-alcoholic fatty liver disease; HCC: hepatocellular cancer; BMI: body mass index; AFP: alpha feto protein

of non 10-year survivors (48.7\%) with mean time to recurrence of $15.3 \pm 14.8$ months and $61(76.3 \%)$ had treatment of the recurrence. Recurrence rate was $23.4 \%$ after transplant, $50.9 \%$ after resection and $85.7 \%$ after just locoregional therapy. For the liver transplant patients, $73.3 \%$ of recurrences received the following treatments: resections-5, RFA-2, external radiation-2 and systemic therapy-2. In the patients who received liver resection, $80.7 \%$ of recurrences were treated with the following; RFA-19, systemic therapy-15, TACE-14, repeat resection-11, radiation-3, Yttrium-90 radioembolization-2, and cryotherapy-1. Thirty-five liver resection patients had more than one recurrence and received: chemotherapy-17, RFA-7, TACE-7, repeat resection-2 and Yttrium-90 radioembolization-1. Of the 7 patients who had only locoregional therapy, 5 patients had RFA and 2 patients had TACE as their initial treatment. One patient had RFA for a $1.0 \mathrm{~cm}$ lesion and died 14 years later from cardiac problems. The other 6 patients had recurrences 3-11 years after their initial LRT and had subsequent procedures. Predictors of recurrence included alcohol abuse, HCV, 
Table 6. Predictors of 10-year survival after hepatic resection

\begin{tabular}{|c|c|c|}
\hline & Univariate odds-ratio $(95 \% \mathrm{Cl})$ & Multivariate odds-ratio $(95 \% \mathrm{Cl})$ \\
\hline Age $\geq 65$ & $0.35(0.14-0.88)$ & $0.27(0.43-4.50)$ \\
\hline Sex (Males) & $0.99(0.40-2.45)$ & \\
\hline Hepatitis B & $2.35(1.01-5.45)$ & $2.14(0.75-6.10)$ \\
\hline Hepatitis C & $0.43(0.139-1.32)$ & \\
\hline Alcohol history & $1.16(0.48-2.79)$ & \\
\hline NASH/NAFLD & $0.20(0.03-1.55)$ & \\
\hline HCC found with surveillance & $1.59(0.53-4.76)$ & \\
\hline $\mathrm{BMI} \geq 25$ & $0.27(0.10-0.72)$ & $0.32(0.10-1.02)$ \\
\hline $\mathrm{BMI} \geq 30$ & $0.36(0.08-1.64)$ & \\
\hline Smoking & $0.33(0.13-0.80)$ & $0.25(0.09-0.74)$ \\
\hline Diabetes & $0.08(0.01-0.57)$ & $0.15(0.02-1.22)$ \\
\hline Hyperlipidemia & $0.82(0.31-2.22)$ & \\
\hline Hypertension & $0.36(0.15-0.85)$ & $0.63(0.22-1.82)$ \\
\hline Normal AFP & $0.65(0.28-1.53)$ & \\
\hline Size $\geq 5 \mathrm{~cm}$ & $0.96(0.41-2.22)$ & \\
\hline Met Milan criteria & $1.03(0.43-2.49)$ & \\
\hline Rupture & $0.60(0.13-2.78)$ & \\
\hline Single tumor & $1.09(0.38-3.14)$ & \\
\hline Vascular invasion & $<0.01$ (0-inf) & \\
\hline Recurrence & $0.88(0.38-2.00)$ & \\
\hline
\end{tabular}

Significant values are in bold. NASH: non-alcoholic steatohepatitis; NAFLD: non-alcoholic fatty liver disease; HCC: hepatocellular cancer; BMI: body mass index; AFP: alpha feto protein

screenable diagnosis, symptoms at the diagnosis, size $\geq 5 \mathrm{~cm}$, treatment modalities (transplantation: $23.4 \%$, resection: 50.9\%, LRT: 85.7\%). Age $\geq 65$-year, AJCC staging, hypertension, hyperlipidemia, normal AFP, ethnicity, tumor rupture, presence of single tumor, or vascular invasion were not significant predictors of 10-year survival. For transplantation, there was significant difference on tumor recurrence with $13.9 \%$ had recurrence for 10-year survivors and $35.7 \%$ had recurrence on non-survivors $(P=0.05)$. However, hepatic resection did not have significant difference on recurrence $(P=0.92)$. There was no difference between 10-year survivors and non-survivors regarding treatment status of recurrence for both transplant and hepatic resection. For transplantation, time to recurrence did not have significant difference between 10 -year survivors and non-survivors. However, hepatic resection had significant difference $(P<0.001)$ between 10-year survivors [median: 938, interquartile range (IQR): 730-2155] and non-survivors (median: 357, IQR: 155-514). There was significant difference $(P>0.001)$ between 10-year survivors (median: 4065, IQR: 2,678-5,762) and non-survivors (median: 453, IQR: 174-1315) for recurrence free survival.

\section{DISCUSSION}

\section{Characteristics of 10 -year survivors vs. non-survivors}

Survival after HCC has generally been related to the therapies that patients receive and which therapy they receive is mainly dependent on tumor characteristics and underlying liver function. Because HCC is such a heterogeneous neoplasm, the underlying liver function is further influenced by etiology of liver disease and external factors such as alcohol, smoking, and metabolic factors. When all things were considered in this study, patients who survived 10 years after diagnosis were more likely to be younger. Ten-year survivors also had smaller tumor size and fewer of them exceeded $5 \mathrm{~cm}$. They may also have better underlying liver function as evidenced by lower liver enzymes and higher platelet count however fibrosis markers (FIB-4 and APRI) did not seem to differ between survivors and non-survivors. Previous studies have suggested differences in long term survival based on etiology of chronic liver disease with a better prognosis in those with viral hepatitis $\mathrm{B}$ or $\mathrm{C}$ compared to those with NASH or $\mathrm{ALD}^{[20]}$. Others have shown that underlying liver function can prognosticate long term survival ${ }^{[14]}$. Wu et al ${ }^{[21]}$, in an evaluation of 8450 HCC patients long-term, determined that 10-year survival was dependent on the number of lesions, the presence of 
cirrhosis, child pugh classification and the time elapsed before first recurrence or metastasis. In this study, however, proportion of previous HBV or HCV infection did not differ in 10-year survivors and nonsurvivors. Non-survivors were more likely to have metabolic factors of diabetes and hypertension. Obesity, smoking and alcohol use did not seem to differ between survivors and non-survivors. However, after multivariate analysis, 10-year survivors were younger and less likely to have diabetes. Hypertension, size $\geq$ $5 \mathrm{~cm}$ and meeting Milan criteria were no longer significant after multivariate analysis.

\section{Treatment modality and survival}

This current study attempted to characterize all 10-year survivors as previous studies have described 10-year survival after a particular modality: resection, transplant or RFA. Our study showed long-term survivors mostly occur after resection or transplant, but $10 \%$ of our cohort survived long-term with only locoregional therapy. Baseline characteristics in these three groups differed because of requirements for each of the therapies. To avoid confounding factors and bias, we conducted separate analyses for liver transplantation and resection.

Selection of patients for liver transplantation varies depending on the transplant center but generally requires AJCC stage I or II and the absence of macrovascular invasion, tumor rupture, high AFP, morbid obesity and severe medical comorbidities. In our center, we specifically require patients to have BMI 35 or less and AFP $<1000 \mathrm{ng} / \mathrm{mL}$. In this study, only recurrence was a predictor of 10-year survival after transplantation. Surveillance, hypertension were no longer significant after multivariate analysis.

Previous studies have suggested that 10-year survival after liver resection was primarily dependent on tumor characteristics. Zheng et al. ${ }^{[22]}$, in 212 patients who underwent liver resection for HCC, reported $23 \%$ 10-year survival and predictors of survival included tumors $<5 \mathrm{~cm}$, solitary tumors and the absence of vascular invasion. However, more than $20 \%$ of 10 -year survivors had microvascular invasion, poor tumor differentiation, AFP greater than $1000 \mathrm{ng} / \mathrm{mL}$ and tumor size greater than $10 \mathrm{~cm}$. Long-term survival may also be influenced by surgical expertise, as Chapman et al. ${ }^{[23]}$ reported that centers with high volumes of resections for HCC had significantly improved 10-year survival after hepatic resection. In our study, however, the univariate analysis on hepatic resection suggested that Age $\geq 65, \mathrm{HBV}, \mathrm{BMI} \geq 25$, smoking, and diabetes were associated with 10-year survival. With the multivariate analysis, only lower BMI and smoking were predictive of non-survival and all of the other tumor characteristics and recurrence did not affect survival.

This study did not compare 10-year survivors versus nonsurvivors in locoregional therapy specifically because we had a large heterogeneous group of patients who underwent locoregional therapy. Previous studies have demonstrated 10-year survival after ablative therapies, but these have typically involved patients with small tumors. Chen et al. ${ }^{[14]}$ in 271 patients with BCLC stage 0 patients with tumors $<2.0 \mathrm{~cm}$, reported a $56.4 \%$ 10-year survival. While Shiina et al. ${ }^{[24]}$ used a more liberal criteria of ablating up to $5 \mathrm{~cm}$ tumors and noted a 10 -year survival of $27.3 \%$ in 1170 patients.

\section{Recurrence}

Recurrence of HCC occurred in both 10-year survivors and non-survivors, but later recurrence with aggressive treatment may have allowed for 10 -year survival. Zheng et al ${ }^{[22]}$ in 212 patients who underwent liver resection showed that $77 \%$ of the short term survivors developed recurrence within 2 years while $42 \%$ of the 10 year survivors developed recurrence most of whom had intrahepatic recurrences that were treatable. In a study of 878 patients with HCC, Lee et al. ${ }^{[25]}$ reported a $19.8 \%$ recurrence after transplant compared to a $64.9 \%$ recurrence after resection and suggested that transplant may have a protective effect against late recurrence of early stage HCC. Risk factors for recurrence included multiple tumors, tumor size, histologic features (grade, extent, vascular invasion) and preoperative AFP. Our study also showed 
lower recurrence rate after liver transplantation compared to hepatic resection and the importance of tumor recurrence on 10-year survival, especially after transplantation. Later recurrence was also associated with 10-year survival after liver resection. Tumor size $\geq 5 \mathrm{~cm}$ was associated with recurrence probably because these patients were ineligible for liver transplantation. Unlike previous reports, our study also included detailed information on comorbidities and risk factors and we also found that alcohol consumption was a predictor of recurrence.

\section{Limitations}

This study was limited in that it was a single center study in a unique and diverse patient population in the Pacific which may limit generalizability. Our population had a large proportion of Asian and Pacific Islanders compared to a typical US study. We also had a high proportion of noncirrhotic HBV-related HCC patients, who were more likely to be candidates for resection. Geographic isolation of the entire state and smaller remote islands may also have limited access to care in different ways than larger states or countries. Finally, we reported all-cause mortality, so it is unclear if the non-10-year survivors died from HCC related issue or another problem.

In conclusion, long-term survivors mostly occur after resection or transplant, but $10 \%$ of our cohort survived 10 years with only locoregional therapy. Recurrence of HCC occurred in both 10-year survivors and non-survivors, but later recurrence with aggressive treatment of the recurrence may have allowed for 10-year survival. Finally, long-term survival and recurrence after HCC may be influenced by other comorbidities such as diabetes, smoking and alcohol use which may affect both the tumor and the overall health of the individual but larger studies would be needed to further investigate this.

\section{DECLARATIONS}

\section{Authors' contributions}

Research design, statistical analysis, manuscript drafting, editing: Sempokuya T

Research supervision, research design, statistical analysis, manuscript drafting and editing: Wong LL

\section{Availability of data and materials}

Not applicable.

\section{Financial support and sponsorship}

NIH 3P30CA071789-12S6.

\section{Conflicts of interest}

Dr. Wong is on the speakers bureau for Eisai.

\section{Ethical approval and consent to participate}

This study was approved by the university of hawaii at manoa institutional review board.

\section{Consent for publication}

Not applicable.

\section{Copyright}

(c) The Author(s) 2019.

\section{REFERENCES}

1. Bray F, Ferlay J, Soerjomataram I, Siegel RL, Torre LA, et al. Global cancer statistics 2018: GLOBOCAN estimates of incidence and mortality worldwide for 36 cancers in 185 countries. CA Cancer J Clin 2018;68:394-424. 
2. White DL, Thrift AP, Kanwal F, Davila J, El-Serag HB. Incidence of hepatocellular carcinoma in all 50 united states, from 2000 through 2012. Gastroenterology 2017;152:812-20.

3. Heimbach JK, Kulik LM, Finn RS, Sirlin CB, Abecassis MM, et al. AASLD guidelines for the treatment of hepatocellular carcinoma. Hepatology 2018;67:358-80.

4. Herrero JI, Sangro B, Pardo F, Quiroga J, Iñarrairaegui M, et al. Liver transplantation in patients with hepatocellular carcinoma across Milan criteria. Liver Transpl 2008;14:272-8.

5. Altekruse SF, McGlynn KA, Dickie LA, Kleiner DE. Hepatocellular carcinoma confirmation, treatment, and survival in surveillance, epidemiology, and end results registries, 1992-2008. Hepatology 2012;55:476-82.

6. Singal AG, Pillai A, Tiro J. Early detection, curative treatment, and survival rates for hepatocellular carcinoma surveillance in patients with cirrhosis: a meta-analysis. PLoS Med 2014;11:e1001624.

7. Tabrizian P, Jibara G, Shrager B, Schwartz M, Roayaie S. Recurrence of hepatocellular cancer after resection: patterns, treatments, and prognosis. Ann Surg 2015;261:947-55.

8. Fernandez-Sevilla E, Allard MA, Selten J, Golse N, Vibert E, et al. Recurrence of hepatocellular carcinoma after liver transplantation: is there a place for resection? Liver Transpl 2017;23:440-7.

9. Chagas AL, Felga GEG, Diniz MA, Silva RF, Mattos AA, et al. Hepatocellular carcinoma recurrence after liver transplantation in a brazilian multicenter study: clinical profile and prognostic factors of survival. Eur J Gastroenterol Hepatol 2019;31:1148.

10. Foerster F, Hoppe-Lotichius M, Vollmar J, Marquardt JU, Weinmann A, et al. Long-term observation of hepatocellular carcinoma recurrence after liver transplantation at a European transplantation centre. United Eur Gastroenterol J 2019;7:838-49.

11. Zhang JA, Kwee SA, Wong LL. Late recurrence of hepatocellular carcinoma after liver transplantation. Hepatoma Res 2017;3:58-66.

12. Alshahrani AA, Ha SM, Hwang S, Ahn CS, Kim KH, et al. Clinical features and surveillance of very late hepatocellular carcinoma recurrence after liver transplantation. Ann Transplant 2018;23:659-65.

13. Xu XF, Xing H, Han J, Li ZL, Lau WY, et al. Risk factors, patterns, and outcomes of late recurrence after liver resection for hepatocellular carcinoma: a multicenter study from china. JAMA Surg 2019;154:209-17.

14. Chen PC, Chiu NC, Su CW, Huang YH, Hou MC, et al. Albumin-bilirubin grade may determine the outcomes of patients with very early stage hepatocellular carcinoma after radiofrequency ablation therapy. J Chin Med Assoc 2019;82:2-10.

15. Maluccio MA, Zang Y, Pi W, Tann M, Kubal C, et al. Survival in patients with hepatocellular carcinoma (HCC): a report of 1444 patients treated within a multidisciplinary program. J Clin Oncol 2017;35:e15652-e15652.

16. Kamath PS, Wiesner RH, Malinchoc M, Kremers W, Therneau TM, et al. A model to predict survival in patients with end-stage liver disease. Hepatology 2001;33:464-70.

17. Sterling RK, Lissen E, Clumeck N, Sola R, Correa MC, et al. Development of a simple noninvasive index to predict significant fibrosis in patients with HIV/HCV coinfection. Hepatology 2006;43:1317-25.

18. Mazzaferro V, Bhoori S, Sposito C, Bongini M, Langer M, et al. Milan criteria in liver transplantation for hepatocellular carcinoma: an evidence-based analysis of 15 years of experience. Liver Transpl 2011;17:S44-57.

19. Kanda Y. Investigation of the freely available easy-to-use software 'EZR' for medical statistics. Bone Marrow Transplant 2013;48:452-8.

20. Hassan I, Gane E. Improving survival in patients with hepatocellular carcinoma related to chronic hepatitis C and B but not in those related to non-alcoholic steatohepatitis or alcoholic liver disease: a 20-year experience from a national programme. Intern Med J 2019.

21. Wu KT, Wang CC, Lu LG, Zhang WD, Zhang F-J, et al. Hepatocellular carcinoma: clinical study of long-term survival and choice of treatment modalities. World J Gastroenterol 2013;19:3649-57.

22. Zheng J, Kuk D, Gönen M, Balachandran VP, Kingham TP, et al. Actual 10-year survivors after resection of hepatocellular carcinoma. Ann Surg Oncol 2017;24:1358-66.

23. Chapman BC, Paniccia A, Hosokawa PW, Henderson WG, Overbey DM, et al. Impact of facility type and surgical volume on 10-year survival in patients undergoing hepatic resection for hepatocellular carcinoma. J Am Coll Surg 2017;224:362-72.

24. Shiina S, Tateishi R, Arano T, Uchino K, Enooku K, et al. Radiofrequency ablation for hepatocellular carcinoma: 10-year outcome and prognostic factors. Am J Gastroenterol 2012;107:569-77.

25. Lee K, Lee KB, Yi NJ, Suh KS, Jang JJ. Prognosis of hepatocellular carcinoma after liver transplantation: comparative analysis with partial hepatectomy. J Pathol Transl Med 2017;51:79-86. 